M. G. KERR ET $A L$. : STUDIES OF THE INFERIOR VENA CAVA
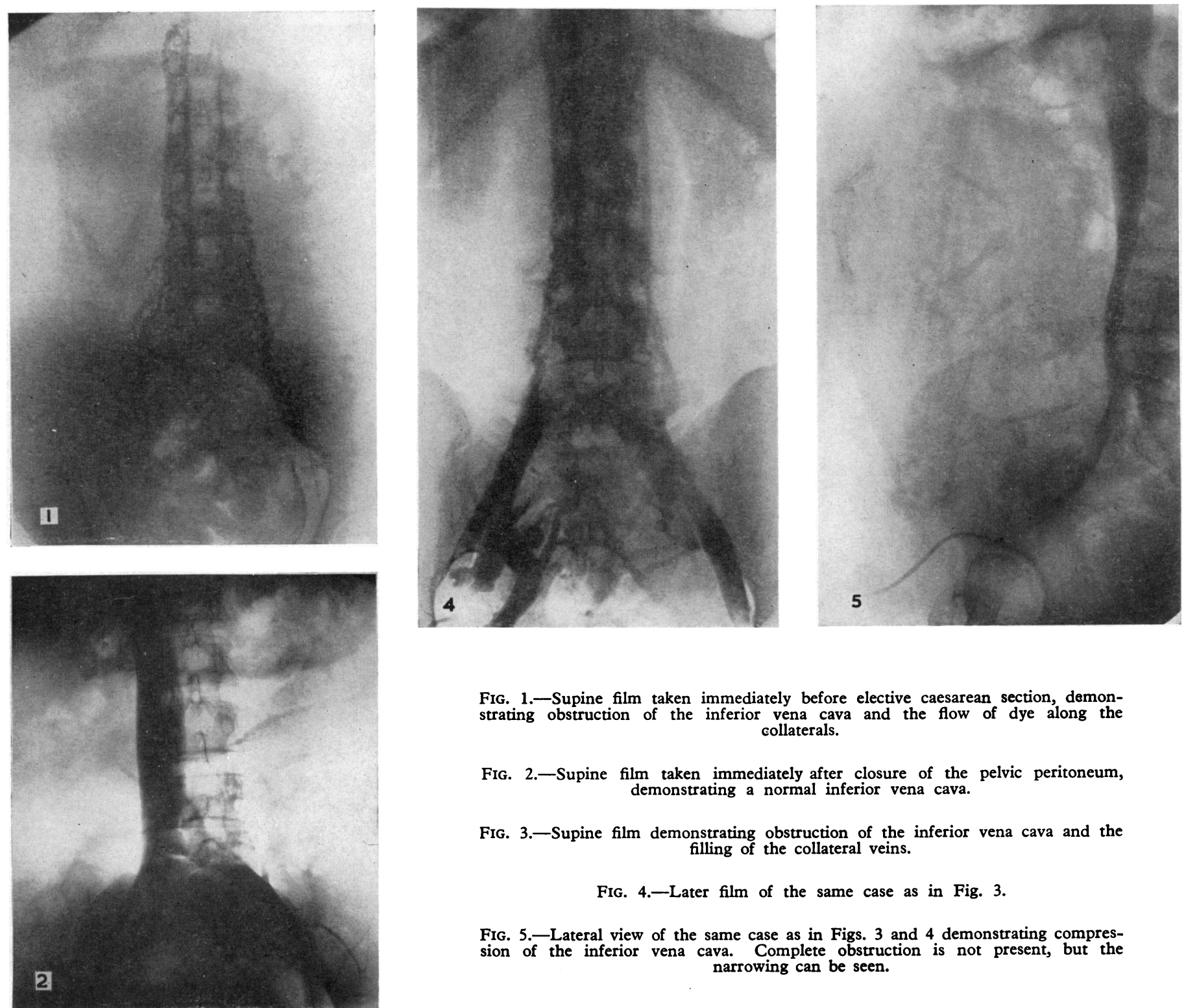

Fig. 1.- Supine film taken immediately before elective caesarean section, demonstrating obstruction of the inferior vena cava and the flow of dye along the collaterals.

FIG. 2.- Supine film taken immediately after closure of the pelvic peritoneum, demonstrating a normal inferior vena cava.

FIG. 3.-Supine film demonstrating obstruction of the inferior vena cava and the filling of the collateral veins.

Fig. 4.-Later film of the same case as in Fig. 3.

Fig. 5.-Lateral view of the same case as in Figs. 3 and 4 demonstrating compression of the inferior vena cava. Complete obstruction is not present, but the narrowing can be seen.
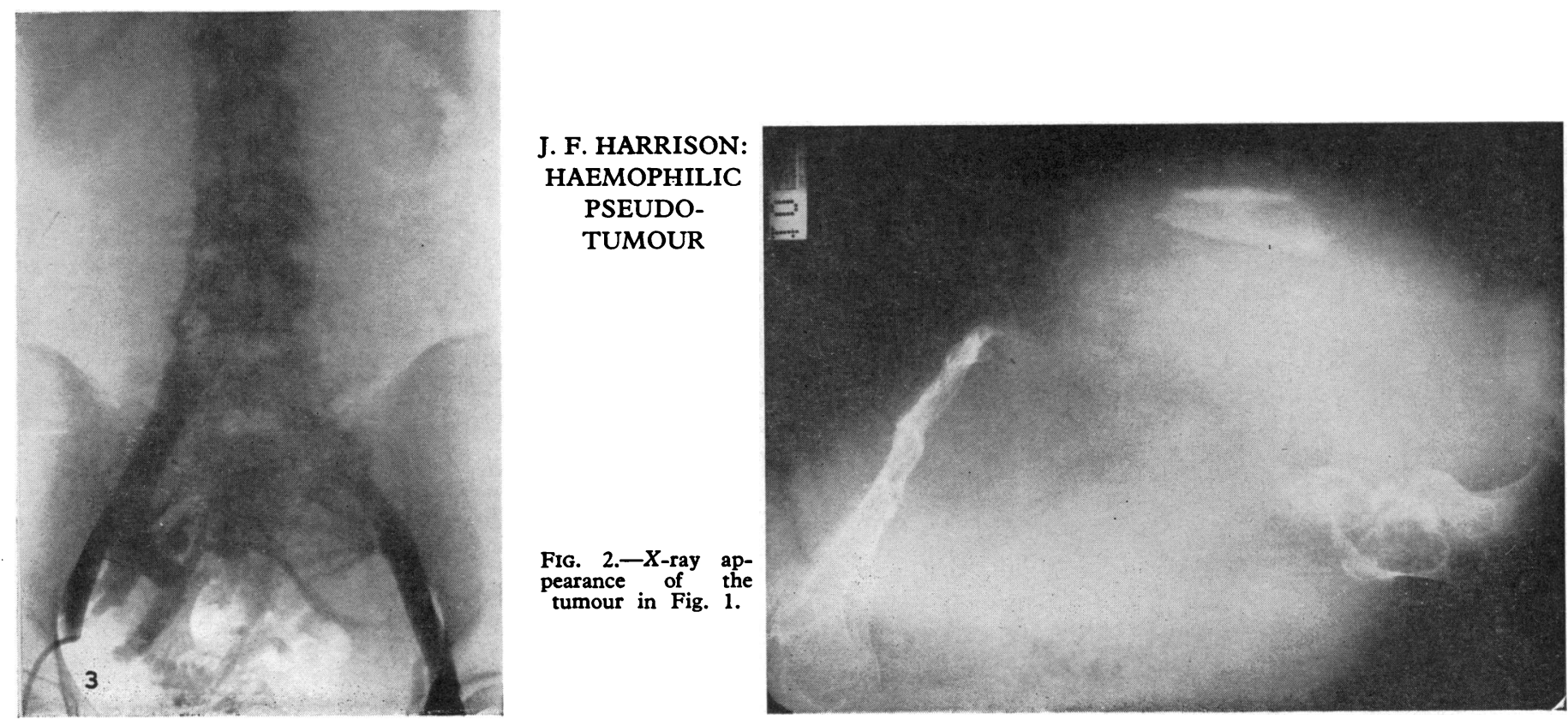
Syndrome II.-Chylous reflux with lymphatic deficiency. These patients had congenital or very early lymphoedema of several limbs, chylous effusions, and hypoproteinaemia. Lymphangiography showed extensive aplasia or hypoplasia of the lymphatic system. The prognosis in this group appears to be worse than in syndrome I.

Detailed case reports are recorded elsewhere and references given.

We are grateful to many colleagues, both physicians and surgeons, too numerous to mention by name, who referred patients for investigation and treatment. Dr. J. E. Dunphy (Dunphy and Foster, 1962, Case 12), Dr. R. Goldrick (Case 13), and Mr. J. H. Williams (Case 14) were kind enough to consult us about patients under their care and later to supply details of the clinical courses of the patients. Many members of our units, and of the radiological departments of our hospitals, helped with the investigation and clinical care of the patients. We wish to thank them for their assistance.
REFERENCES

Allen, E. V. (1934). Arch. intern. Med., 54, 606.

Dunphy, J. E., and Foster, J. H. (1962). Surgical correction of cutaneous chylous reflux into thigh. Film presented at Clin. Congress. Amer. Coll. Surgeons.

Hirschler, A., and Buday, K. (1889). Quoted by Rusznyák, Földi, and Szabo (1957).

Jantet, G. H., Taylor, G. W., and Kinmonth, J. B. (1961). F. cardiovasc. Surg. (Torino), 2, 27

Kinmonth, J. B. (1960). F. roy. Coll. Surg. Edinb., 5, 287. - and Gough, M. H. (1962). Unpublished data. (1963). Unpublished data.

Rob, C. G., and Simeone, F. A. (1962). Vascular Surgery, Arnold, London; Williams and Wilkins, Baltimore, Md., U.S.A.

Taylor, G. W., and Jantet, G. H. (1964). f. cardiovasc. Surg. In press.

Tracy, G. D., and Marsh, J. D. (1957). Brit. F. Surg., 45, 1. artorell, F. (1963). Communication to Int. Cardiovasc. Soc., Rome (to be published in 7 . cardiovasc. Surg.)

Rusznyák, I., Földi, M., and Szabó, G. (1957). Physiologie und Pathologie des Lymphkreislaufes. Akadémiai Kiadó, Budapest.

Servelle, M. (1963). f. cardiovasc. Surg., 4, 702.

Sharpey-Schafer, E. P., and Kinmonth, J. B. (1957). Demonstration to Physiological Society, London.

Waldmann, T. A., Steinfeld, J. L., Dutcher, T. F., Davidson, J. D., and Gordon, R. S. (1961). Gastroenterology, 41, 197.

\title{
Studies of the Inferior Vena Cava in Late Pregnancy
}

\author{
M. G. KERR,* M.B., B.SC., F.R.C.S.ED., M.R.C.O.G. ; D. B. SCOTT, † M.D., F.F.A. \\ ERIC SAMUEL, $\ddagger$ M.D., F.R.C.P.ED., F.R.C.S., F.R.C.S.ED., F.F.R.
}

[With Special Plate]

Brit. med. F., 1964, 1, 532-533

For several years the concept of inferior vena caval occlusion in the supine position in late pregnancy has been current in obstetric teaching. It has been generally thought that severe occlusion occurs in a small minority of cases, giving rise to the well-known supine hypotensive syndrome (Howard, Goodson, and Mengert, 1953). A minor degree of caval obstruction has been believed to occur in at least $50 \%$ of patients (Holmes, 1960).

Recent manometric studies on inferior vena caval pressure in late pregnancy have, however, indicated a rather different state of affairs (Scott and Kerr, 1963). Inferior vena caval pressures were recorded in a number of patients in the supine position in late pregnancy, and each of these records demonstrated two constant features. (1) In the supine position respiratory pressure changes were not transmitted from the thorax to the caudal part of the inferior vena cava ; whereas in the lateral position these cyclical changes were readily detectable at that level. (2) In the supine position the pressure in the inferior vena cava was consistently high (about $20 \mathrm{~cm}$. of water), and this pressure could not be raised by manual occlusion of the inferior vena cava under direct vision, proximal to the level of recording. These findings were interpreted as indicating that in late pregnancy, in the supine position, the inferior vena cava is normally completely occluded and consequently the venous return is ensured by alternative collateral channels.

In an attempt to elucidate this situation it was necessary to supplement these observations on inferior vena caval pressure with an investigation of inferior vena caval flow. This has been achieved by radiological studies of the inferior vena cava in late pregnancy.

* Lecturer in Department of Obstetrics, University of Edinburgh.

+ Consultant Anaesthetist, Royal Infirmary, Edinburgh.

‡ Radiologist-in-Charge, Royal Infirmary, Edinburgh.

\section{Methods}

In an attempt to minimize any foetal hazards from exposure to $x$ rays, our earliest observations were made on four patients known to have an abnormal foetus and in whom pregnancy was to be terminated (two cases of anencephaly; one cervical meningocele; one encephalocele). With these patients three serial films were taken at one-second intervals to follow the venous flow. From our experience with these cases, it was possible to obtain an adequate venogram with one exposure.

In subsequent cases it was felt justifiable to permit a single exposure of a supine film immediately prior to an elective caesarean section performed for various obstetric reasons, as it was considered that the radiation from one single flat film of the abdomen constituted no significant hazard to the mother or to the foetus immediately prior to birth. This procedure was performed on eight patients.

Catheterization of both femoral veins was achieved by percutaneous puncture, using a Seldinger needle 160 and a " polythene" catheter of the same diameter. Simultaneous puncture of both femoral veins was undertaken and both catheters were passed along the femoral vein as far as the junction of the internal and external iliac veins, this site being determined approximately by mensuration. Both catheters were then connected by a Y-piece to a $50-\mathrm{ml}$. syringe. Then $20 \mathrm{ml}$. of $60 \%$ "urografin" was injected by hand pressure and a single film was taken as the injection was completed. In cases where more than one film was possible-that is, those with an abnormal foetus-the first film was taken when $15 \mathrm{ml}$. of dye had been injected, and the second film on completion of the injection. The above procedure was carried out under anaesthesia immediately prior to caesarean section. After the first film had been taken caesarean section was carried out, the catheters being left in situ and isolated from the operation 
field. The catheters were intermittently perfused with saline to prevent clotting during the operation. After the uterovesical peritoneum had been reconstituted and before closure of the abdomen, the uterus was lifted forwards by long-stay sutures in the round ligaments. A second bolus of dye was injected and another film taken. This allowed the inferior vena cava to be visualized in the absence of any compression by the uterus.

No untoward reactions were noted in the present series, and the $20 \mathrm{ml}$. could be injected in approximately one and a half seconds.

Manual injection by means of the Stirling hand-pump was used on one occasion, but it was felt that the pressure produced by this syringe was far greater than the physiological pressure and for this reason it was discarded.

It should be noted that the eight patients undergoing caesarean section, and two of those with abnormal foetuses, were between the 38th and 40th weeks of pregnancy. The remaining two patients with abnormal foetuses were at the 32 nd week, but both had gross hydramnios. In every patient in this series, therefore, the fundus of the uterus was within 2 in. $(5 \mathrm{~cm}$.) of the xiphisternum.

\section{Radiological Findings}

It was found that in 10 out of the 12 cases examined complete obstruction to the passage of medium occurred at the level of the bifurcation of the inferior vena cava (Special Plate, Figs. 1, 3, and 4). In the other two instances a degree of partial obstruction was noticed, the left common iliac being more markedly affected than the right. The venous return passed by means of the ascending lumbar veins and the complex of veins surrounding the spinal canal. These veins terminated at a higher level in the azygos veins.

Two well-marked veins, the ascending lumbar veins, arose from each common iliac immediately proximal to the bifurcation, and in one instance catheterization of this vessel on the left side was inadvertently performed.

In the eight patients undergoing caesarean section a film was obtained after emptying the uterus. All of these post-operative films demonstrated a normal patent inferior vena cava, although a minute quantity of dye could be seen passing into the lower parts of the ascending lumbar veins (Special Plate, Fig. 2).

In those cases with abnormal foetuses, where the radiation hazard was not thought to be of importance, films were also taken in the lateral position with the patient rotated so that the uterine weight fell forward. These films demonstrated the passage of dye up the inferior vena cava, although there still appeared to be some degree of compression of the vein by the gravid uterus even in the lateral position (Special Plate, Fig. 5). It is of interest to observe that this compression is clearly evenly distributed along the length of the inferior vena cava as far as the fundus of the uterus. In other words, the vein is not occluded at a single point near its origin, but evenly throughout its course as high as the fundus reaches.

\section{Discussion}

These observations on blood-flow confirm our previous studies on blood-pressure in the inferior vena cava. They establish the fact that, in the supine position in late pregnancy, it is normal for the inferior vena cava to be virtually completely occluded. The venous return is redirected via collateral channels, principally the azygos and vertebral venous systems.

These findings make untenable any explanations of the supine hypotensive syndrome which are based on occasional occlusion of the inferior vena cava. It appears that inferior vena caval occlusion is the rule rather than the exception, and that it is the variable adequacy of the collateral channels which determines the effect of the supine position on the venous return.

This concept forces another consequence. The renal veins drain into the inferior vena cava and have no adequate alternative drainage. Consequently, obstruction to the inferior vena cava at the level of entry of the renal veins automatically implies increased renal venous pressure. The effects of posture on renal function in late pregnancy have already been described (Pritchard, Barnes, and Bright, 1955), and we are currently pursuing these investigations. Finally, it is apparent that posture has profound effects on the circulation in late pregnancy, and this must be carefully considered in any haemodynamic or renal studies in pregnancy.

\section{Summary}

Radiological studies of the inferior vena cava have been made in 12 patients in late pregnancy.

These studies indicate that the inferior vena cava is normally occluded in the supine position in late pregnancy, and that venous return is via the azygos and vertebral veins.

In the lateral position this obstruction is at least partially relieved.

We wish to acknowledge the help and interest shown by Professor R. J. Kellar and his permission to study his patients. We should also like to thank Dr. Bruce Young and Dr. T. Philp for their assistance and Miss I. R. West and Mrs. H. McKay, the radiographers.

\section{REFERRNCES}

Holmes, F. (1960). F. Obstet. Gynaec. Brit. Cwlth, 67, 254.

Howard, B. K., Goodson, J. H., and Mengert, W. F. (1953). Obstet. and Gynec., 1, 371.

Pritchard, J. A., Barnes, A. C., and Bright, R. H. (1955). F. clin. Invest., 34, 777.

Scott, D. B., and Kerr, M. G. (1963). 7. Obstet. Gynaec. Brit. Cwlth, 70, 